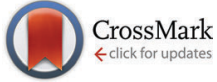

Cite this: Phys. Chem. Chem. Phys., $2015,17,27698$

Received 31st August 2015, Accepted 23rd September 2015 DOI: $10.1039 / c 5 c p 05189 d$

www.rsc.org/pccp

\title{
Attenuating microwave radiation by absorption through controlled nanoparticle localization in PC/PVDF blends
}

\author{
Sourav Biswas, Goutam Prasanna Kar and Suryasarathi Bose*
}

\begin{abstract}
Nanoscale ordering in a polymer blend structure is indispensable to obtain materials with tailored properties. It was established here that controlling the arrangement of nanoparticles, with different characteristics, in co-continuous PC/PVDF (polycarbonate/poly(vinylidene fluoride)) blends can result in outstanding microwave absorption (ca. 90\%). An excellent reflection loss $\left(R_{\mathrm{L}}\right)$ of ca. $-71 \mathrm{~dB}$ was obtained for a model blend structure wherein the conducting (multiwall carbon nanotubes, MWNTs) and the magnetic inclusions $\left(\mathrm{Fe}_{3} \mathrm{O}_{4}\right)$ are localized in PVDF and the dielectric inclusion (barium titanate, BT) is in PC. The MWNTs were modified using polyaniline, which facilitates better charge transport in the blends. Furthermore, by introducing surface active groups on BT nanoparticles and changing the macroscopic processing conditions, the localization of BT nanoparticles can be tailored, otherwise BT nanoparticles would localize in the preferred phase (PVDF). In this study, we have shown that by ordered arrangement of nanoparticles, the incoming EM radiation can be attenuated. For instance, when PANI-MWNTs were localized in PVDF, the shielding was mainly through reflection. Now by localizing the conducting inclusion and the magnetic lossy materials in PVDF and the dielectric materials in PC, an outstanding shielding effectiveness of ca. $-37 \mathrm{~dB}$ was achieved where shielding was mainly through absorption (ca. 90\%). Thus, this study clearly demonstrates that lightweight microwave absorbers can be designed using polymer blends as a tool.
\end{abstract}

\section{Introduction}

Electromagnetic (EM) radiation consists of both electric $(E)$ and magnetic $(H)$ vector components which are oscillating at right angles to each other. The inexhaustible use of electronic and communication devices generates such radiation as an offshoot and leads to a new kind of pollution known as electromagnetic interference (EMI). ${ }^{1-6}$ EMI is undesirable and has emerged as a significant problem in the current era. This eventually leads to malfunction of precise equipment and hence, shielding of emitted radiation has become indispensable. EMI shielding is a route to restrict the flow of electromagnetic fields by unravelling them with a fence through conducting materials. In the past few decades, substantial effort has been made to design lightweight EM shielding materials in these circumstances. ${ }^{7-11}$

EM shielding effectiveness (SE) is dependent on three different parameters, namely reflection $\left(\mathrm{SE}_{\mathrm{R}}\right)$, absorption $\left(\mathrm{SE}_{\mathrm{A}}\right)$ and multiple reflection $\left(\mathrm{SE}_{\mathrm{MR}}\right)$, where multiple reflection can be ignored when $\mathrm{SE}_{\mathrm{A}}$ is $>10 \mathrm{~dB}$ or the thickness of the shielding material is more than the skin depth.,12 $\mathrm{EM}$ radiation can interact with free charge carriers and shield mostly by reflection.

Department of Materials Engineering, Indian Institute of Science, Bangalore 560012, India. E-mail: sbose@materials.iisc.ernet.in; Tel: +91-80-2293 3407
Otherwise shielding by absorption is prominent when vector components of incident radiation interact with electric or magnetic dipoles of the shielding material. ${ }^{13-15}$ Ferromagnetic or ferroelectric particles can generate such kinds of magnetic or electric dipoles. Generation of eddy currents mainly promotes the absorption loss values which are a result of ohmic losses and leads to heating of the material. ${ }^{16-21}$

Metals are of prime interest as shielding materials owing to their high electrical conductivity. However, such types of material have some inconveniences like cumbersome processing conditions, low flexibility, high weight and being prone to corrosion. Whereas, highly flexible, corrosion resistant, lightweight polymer based composites have now gained high research enthusiasm as alternative shielding materials. ${ }^{22-27}$

In this context, high amounts of conducting fillers are being added to insulating polymers to attain high electrical conductivity however, at the cost of deteriorated mechanical properties. High aspect ratios and ability to form continuous network arrangement at very low loadings by carbon nanotubes (CNTs) have led to an innovative change in this area. But the effective aspect ratio is reduced due to the agglomeration of CNTs because of strong van-der Walls' interaction between the nanotubes. This reduction also influences the conductivity values. There are ample literature reports, which address this issue in detail. ${ }^{28-31}$ Generally it is 
believed that the electrical conductivity of CNTs depends on $\pi$-conjugation. ${ }^{32}$ Alternatively, the bulk electrical conductivity can be enhanced by preferential localization of the conducting particles in the preferred phase of an immiscible co-continuous blend. Inherently conducting polymer based composites have also received superior attention due to their high conductivity and permittivity values. ${ }^{33-40}$ But their commercial utility is restricted due to their poor mechanical properties and poor processing abilities.

In light of the existing literature and the associated drawbacks of the existing conventional materials for shielding, we employed co-continuous PC/PVDF blends as a model system to prepare a series of blend nanocomposites for EM shielding. The preferential localization of conducting nanoparticles in the specified phase, AC electrical conductivity is significantly enhanced. Under this framework, the effective concentration of the conducting particles increases, thereby facilitating more interconnections. The key requirements of a microwave absorber are high electrical conductivity and large dielectric and magnetic loss. Hence, in situ PANI wrapped MWNT has been synthesized to render high electrical conductivity in the blends. The latter requisite i.e. high dielectric and magnetic loss is targeted by two nanoscopic particles like $\mathrm{Fe}_{3} \mathrm{O}_{4}$ and barium titanate (BT) in combination with PANI wrapped MWNT. In view of its high polarity, MWNTs prefer to localize in PVDF and hence, ferromagnetic $\mathrm{Fe}_{3} \mathrm{O}_{4}$ nanoscopic particles were added along with MWNTs during the in situ synthesis of PANI to yield hybrid PANI-MWNT- $\mathrm{Fe}_{3} \mathrm{O}_{4}$ particles. The dielectric loss was targeted using BT in the lazy phase of the blend (PC here). There are ample literature reports present where polymer blends were used as microwave absorbers designed only by using one phase of the blend where particles are dispersed, with the other phase being lazy. ${ }^{16,17,29,31,32}$ Here we apply the compartmentalized approach to a high efficient microwave absorber designed by using both phases of an immiscible 60/40 PC/PVDF substrate.

\section{Experimental section}

\section{Materials}

Poly(vinylidene fluoride) (KYNAR-761) (molecular weight $440000 \mathrm{~g} \mathrm{~mol}^{-1}$ ) was procured from Arkema. Polycarbonate (Lexan-143R) was obtained from Sabic, with a MFI of $10 . \mathrm{BaTiO}_{3}$ (100 nm particle size), $\mathrm{Fe}_{3} \mathrm{O}_{4}$ (50-100 nm diameter), 3-aminopropyltriethoxysilane (APTS), 4-dodecylbenzenesulfonic acid (DBSA), aniline, ammonium persulfate (APS), $\mathrm{H}_{2} \mathrm{O}_{2}(28-32 \%$ in water), toluene and $N, N^{\prime}$-dicyclohexylcarbodiimide (DCC) were acquired from Sigma-Aldrich. Ethanol, $N, N$-dimethylformamide, tetrahydrofuran, and chloroform were purchased from commercial sources. Pristine MWNTs were obtained from Nanocyl SA (Belgium).

\section{Synthesis of PANI wrapped MWNT composites}

PANI wrapped MWNT (PANI-MWNT) composites were prepared by in situ emulsion polymerization of aniline. ${ }^{18}$ Typically, 0.2 mole of dopant (DBSA) was homogenized with $500 \mathrm{ml}$ of

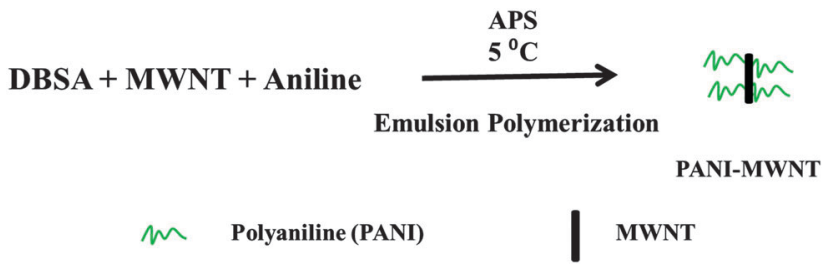

Scheme 1 Synthesis of in situ polymerized PANI-MWNTs.

distilled water. MWNTs were added into the homogenized mixture and bath sonicated for $30 \mathrm{~min}$. Subsequently, 0.1 mole of aniline was added into the mixture and again bath sonicated for $15 \mathrm{~min}$ at $0{ }^{\circ} \mathrm{C}$ temperature. Then the mixture was stirred using a magnetic stirrer for $30 \mathrm{~min}$ to form aniline-DBSA micelles along with MWNTs by keeping the temperature at $0{ }^{\circ} \mathrm{C}$. In a separate beaker 0.1 mole of initiator ammonium peroxydisulfate (APS) was dissolved in $100 \mathrm{ml}$ of water and cooled to $0{ }^{\circ} \mathrm{C}$. After the formation of micelles, APS solution was added to the micelle solution dropwise with continuous stirring throughout the course of the reaction which was typically $8 \mathrm{~h}$. After that a sufficient amount of ethanol was added to stop the reaction and stirring was continued for another 2 h. Finally, the reaction mixture was centrifuged and dried under vacuum at $80{ }^{\circ} \mathrm{C}$ (Scheme 1).

\section{Synthesis of PANI-MWNT- $\mathrm{Fe}_{3} \mathrm{O}_{4}$ composites}

The PANI-MWNT- $\mathrm{Fe}_{3} \mathrm{O}_{4}$ composite was also synthesized by emulsion polymerization of aniline as discussed above except for the fact that the MWNTs were sonicated along with $\mathrm{Fe}_{3} \mathrm{O}_{4}$ in the homogenised DBSA solution (Scheme 2).

\section{Synthesis of BT- $\mathrm{NH}_{2}$ nanoparticles}

A two-step procedure is followed for the synthesis of amine terminated BT nanoparticles. By starting with the dispersion of BT particles in $\mathrm{H}_{2} \mathrm{O}_{2}$ by bath sonication, the dispersed solution was refluxed for $4 \mathrm{~h}$ at $105{ }^{\circ} \mathrm{C}$ followed by vacuum drying. Later hydroxylated BT nanoparticles can undergo refluxing again in the presence of APTS at $80{ }^{\circ} \mathrm{C}$ for $24 \mathrm{~h}$. Centrifugation of the obtained mixture followed by washing with toluene (4 times) for removing the excess APTS and finally the solvent was evaporated under vacuum drying to yield $\mathrm{NH}_{2}$ terminated $\mathrm{BT}$ nanoparticles.

\section{Synthesis of PC-BT- $\mathrm{NH}_{2}$ composites}

Amine terminated BT nanoparticles, as prepared in the previous step, can react with the ester groups of PC by via nucleophilic substitution, resulting in a BT terminated PC chain. ${ }^{41}$ Typically PC

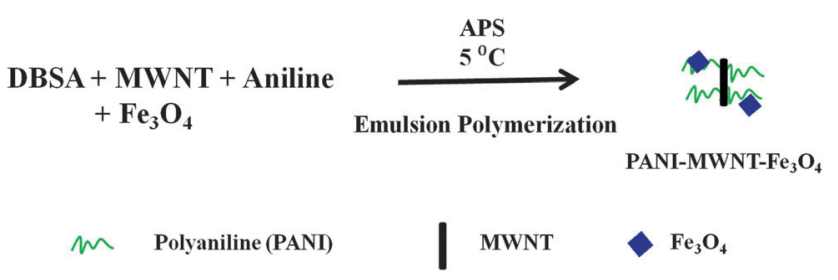

Scheme 2 Synthesis of in situ polymerized PANI-MWNT- $\mathrm{Fe}_{3} \mathrm{O}_{4}$. 


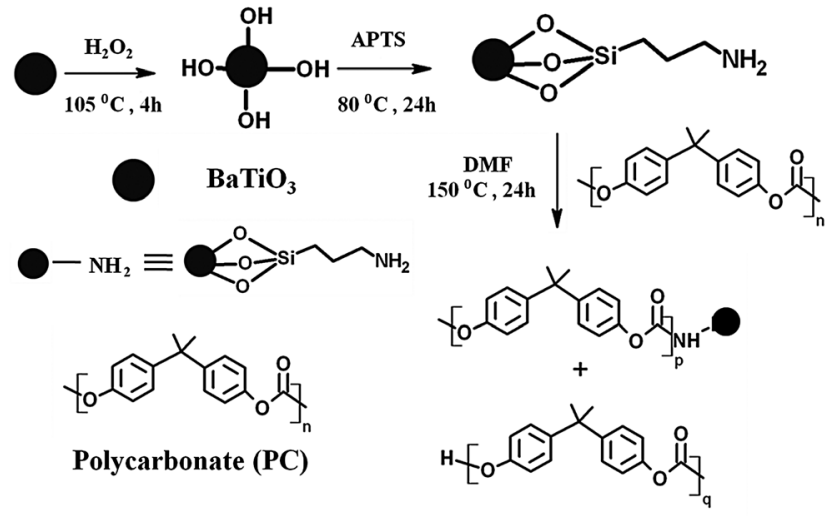

Scheme 3 Synthesis of BT terminated PC composites.

was dissolved in DMF and the amine terminated BT nanoparticles were dispersed in the solution and the resultant solution was bath sonicated for $30 \mathrm{~min}$. After $24 \mathrm{~h}$ of refluxing at $150{ }^{\circ} \mathrm{C}$ the resultant reaction mixture was poured onto a Teflon sheet and vacuum dried at $80{ }^{\circ} \mathrm{C}$ (Scheme 3).

\section{Blend preparation}

PC/PVDF (40/60, wt/wt) blends were processed at $260{ }^{\circ} \mathrm{C}$ and at $60 \mathrm{rpm}$ rotational speed using a melt compounder under (Haake minilab-II). All the blending was done under a $\mathrm{N}_{2}$ atmosphere for $20 \mathrm{~min}$. The above-mentioned nanoparticles were added directly to the constituent polymers. In order to precise localization of nanoparticles in a given phase, we made a few compositions where we used the previously prepared BT terminated PC composites and directly mixed with PVDF. This will eventually lead to localization of the PANI-MWNT- $\mathrm{Fe}_{3} \mathrm{O}_{4}$ in the PVDF phase and BT in the PC phase.

\section{Characterization}

A Tecnai G2F30 at $300 \mathrm{kV}$ was used to acquire Transmission Electron Microscopy (TEM) images on various nanoparticles. A scanning electron microscope (SEM, ULTRA 55) with an accelerating voltage of $10 \mathrm{kV}$ was used to assess the morphology of various blends. EDS (energy dispersive X-ray spectroscopy) was performed with an accelerating voltage of $15 \mathrm{kV}$. X-ray diffraction was done using a XPERT Pro from PANalytical. A $\mathrm{Cu} \mathrm{K} \alpha$ radiation source $(\lambda=1.5406 \AA, 40 \mathrm{kV}$ and $30 \mathrm{~mA})$ was used to determine the XRD pattern of the samples. A Lakeshore Vibratory Sample Magnetometer (VSM) was used to determine the magnetic properties of the samples with an applied force of 8000 to 8000 Oe at room temperature.

An Alpha-N Analyser, Novocontrol (Germany) was used to acquire AC electrical conductivity of various blends in the range of $0.1 \mathrm{~Hz}$ to $10 \mathrm{MHz}$ frequency. All measurements were performed at room temperature. The disk samples were made by compression molding at $260{ }^{\circ} \mathrm{C}$ temperature and uniformly polished prior to measuring the AC electrical conductivity. Melting and crystallization of polymer blends were measured on a TA instruments Q200 differential scanning calorimeter. Thermal analysis was done on an STA $409 \mathrm{PC} \operatorname{Luxx}^{\circledR}$ at $10{ }^{\circ} \mathrm{C} \mathrm{min}^{-1}$.
The apparent zeta potential was measured on a Malvern Zetasizer using water as the solvent.

EM shielding interference was studied by an Anritsu MS4642A vector network analyzer (VNA). A Damaskos MT-07 was used as a toroidal sample holder and was connected with VNA for measurements. Prior to experiment the full setup was calibrated by full SOLT. Generally we used $5 \mathrm{~mm}$ thick toroidal samples which were prepared by compression molding at $260{ }^{\circ} \mathrm{C}$. $S$ parameters $\left(S_{11}, S_{12}, S_{22}\right.$ and $\left.S_{21}\right)$ were measured in the $\mathrm{X}$ and Ku-band of frequency for all the measurements. The total shielding effectiveness and the $R_{\mathrm{L}}$ are measured in $\mathrm{dB}$.

\section{Results and discussion}

\section{Synthesis and characterization}

The in situ synthesis of PANI-MWNTs and PANI-MWNT-Fe $\mathrm{O}_{4}$ is illustrated in Schemes 1 and 2. The TEM micrographs of PANI-MWNTs and PANI-MWNT- $\mathrm{Fe}_{3} \mathrm{O}_{4}$ are depicted in Fig. $1 \mathrm{a}$ and b. A layer of PANI on the surface of MWNTs and $\mathrm{Fe}_{3} \mathrm{O}_{4}$ as indicated is clearly observed in TEM images. Furthermore, successful synthesis of APTS coated BT nanoparticles described in Scheme 3 was also assessed by TEM (Fig. 1c and d). Using an $\mathrm{X}$-ray diffractometer the phase identification was evaluated for PANI-MWNTs and PANI-MWNT- $\mathrm{Fe}_{3} \mathrm{O}_{4}$ nanoparticles in the diffraction range of $10-80^{\circ}$. The characteristics peaks of $\mathrm{Fe}_{3} \mathrm{O}_{4}$ nanoparticles are located at $2 \theta$ of $18.37^{\circ}, 30.09^{\circ}, 35.54^{\circ}, 43.15^{\circ}$, $53.43^{\circ}, 57.01^{\circ}$, and $62.16^{\circ}$ corresponding to (111), (220), (311), (400), (422), (511), and (440) respectively. The peaks at $19.03^{\circ}$, $25.8^{\circ}$ and $42.16^{\circ}$ corresponds to PANI. Fig. 1f shows the magnetic hysteresis of MWNTs and PANI-MWNTs. For MWNTs the following information was obtained. The saturation magnetization $\left(M_{\mathrm{S}}\right)$, 0.345 emu $^{-1}$; remnant magnetization $\left(M_{\mathrm{R}}\right), 0.12 \mathrm{emu}^{-1}$; and coercivity $\left(H_{\mathrm{C}}\right), 133$ Oe and in the case of PANI-MWNTs the $M_{\mathrm{S}}$ is $0.15 \mathrm{emu} \mathrm{g}^{-1}, M_{\mathrm{R}}$ is $0.045 \mathrm{emu} \mathrm{g}^{-1}$ and $H_{\mathrm{C}}$ is 112 Oe. Fig. $1 \mathrm{~g}$ depicts the magnetic properties of PANI-MWNT- $\mathrm{Fe}_{3} \mathrm{O}_{4}$, wherein $M_{\mathrm{S}}$ is $28 \mathrm{emu} \mathrm{g}^{-1}, M_{\mathrm{R}}$ is $4 \mathrm{emu} \mathrm{g}^{-1}$ and $H_{\mathrm{C}}$ is $131 \mathrm{Oe}$. We have also performed dispersion tests of various nanoparticles in different solvents to analyse the interaction between the surface modified nanoparticles and solvents. It is observed that the particles quickly settle in both aqueous and organic media due to poor interaction with the solvent whereas PANI-MWNT- $\mathrm{Fe}_{3} \mathrm{O}_{4}$ remains suspended for a longer time scale after a brief sonication (Fig. 1h). In the case of chloroform, similar observations were noted which clearly indicates that in situ polymerization with PANI, enhances the interaction with solvents resulting in well dispersed particles for longer time scales.

\section{Blend morphology and selective localization of nanoparticles}

Monitoring the phase morphology during blending is the deciding factor of the final properties of the blend. A co-continuous morphology is observed here in the case of control 40/60 PC/PVDF and blends with different nanofillers (Fig. 2a-e). In our previous study ${ }^{41}$ we showed that MWNTs are selectively localized in the PVDF phase due to its polar nature. The high resolution SEM images suggest the presence of MWNTs in the PVDF phase of 

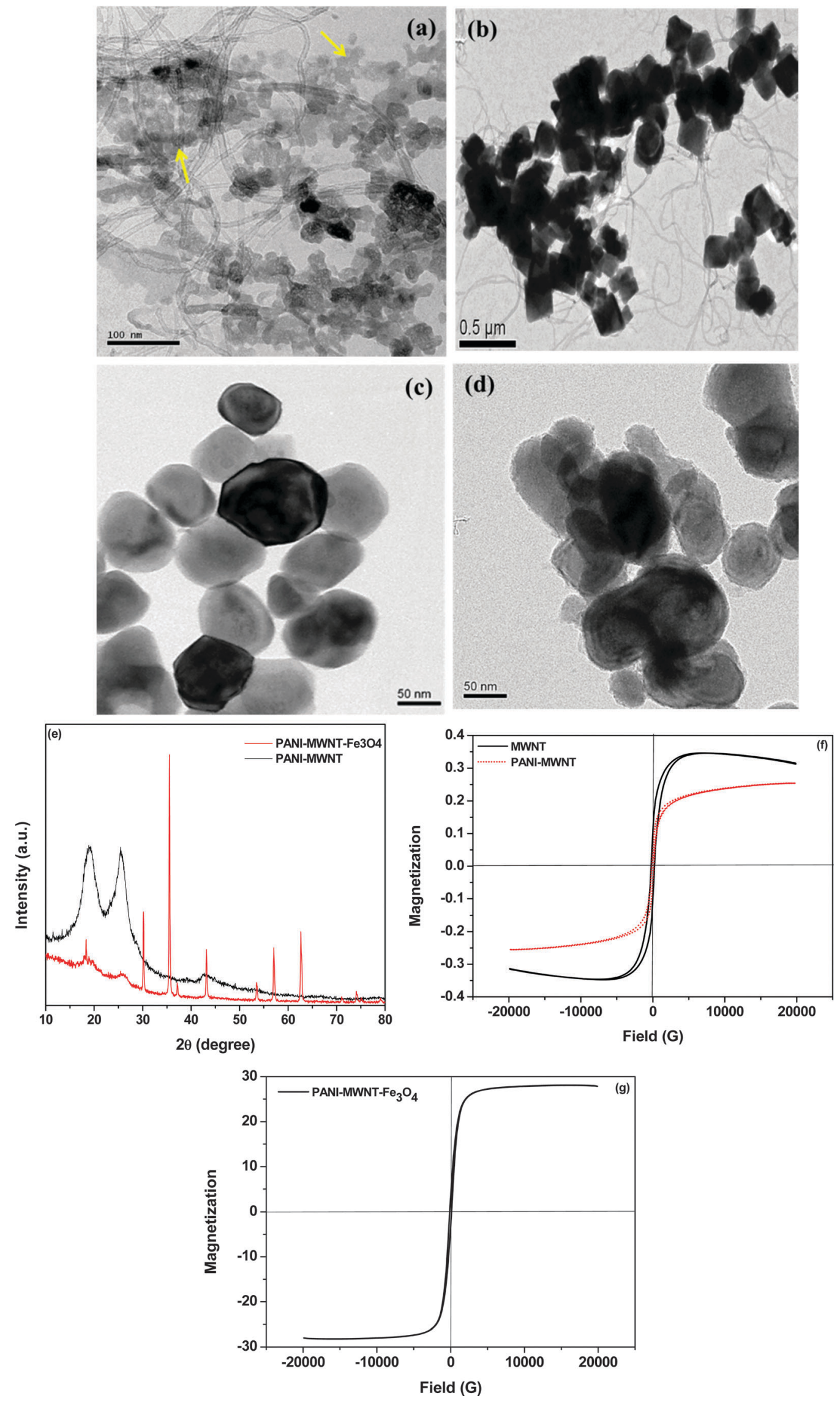
(h)

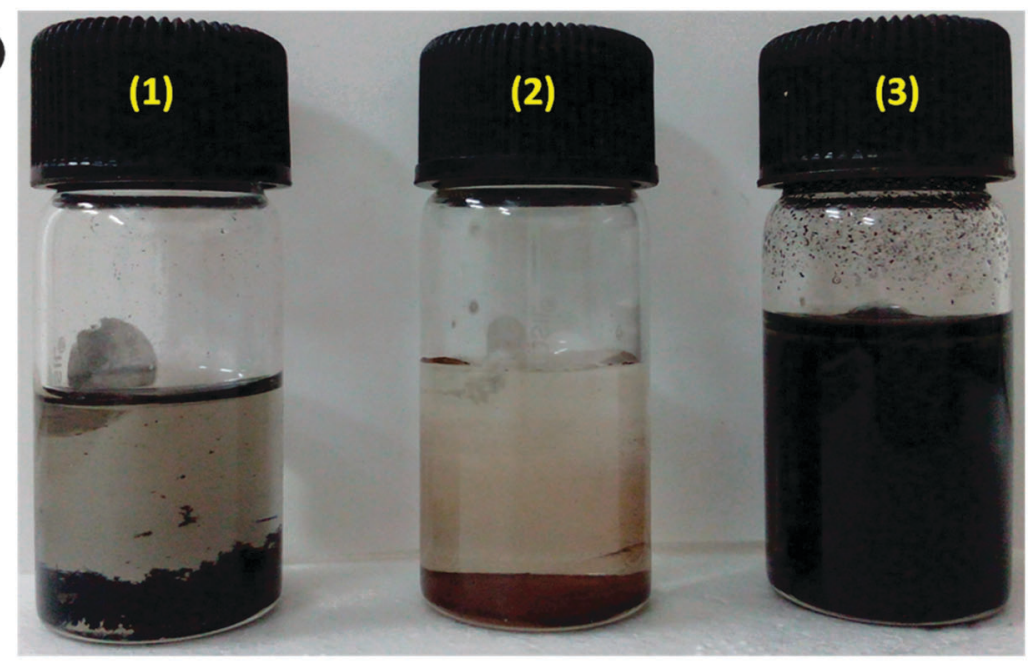

(i)

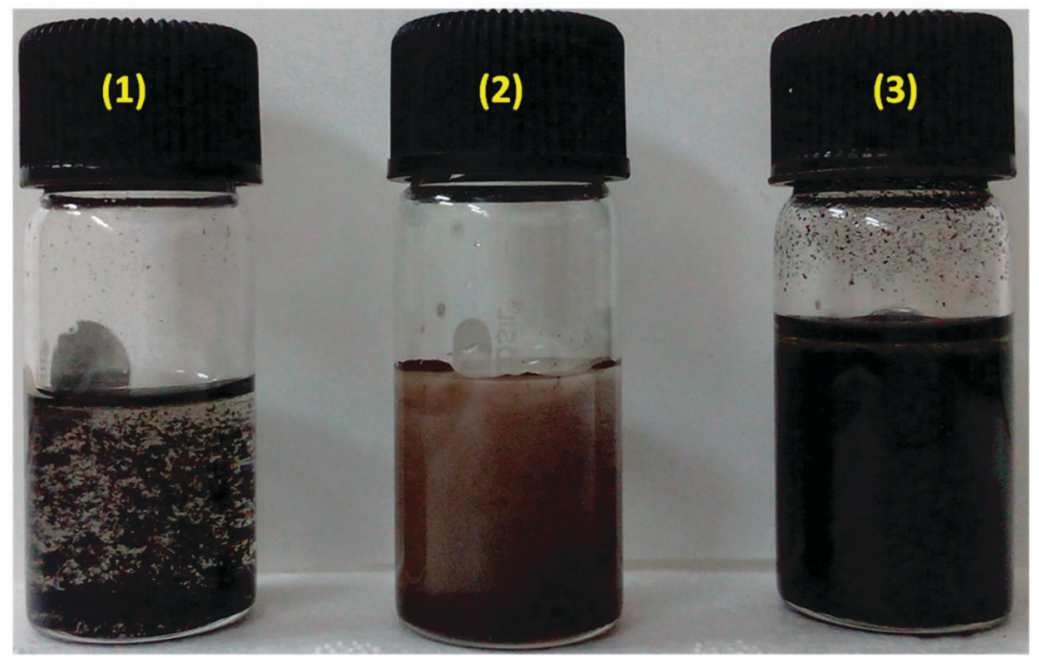

Fig. 1 TEM micrographs of (a) PANI-MWNTs, (b) PANI-MWNT-Fe $\mathrm{O}_{4}$, (c) BT, and (d) BT- $\mathrm{NH}_{2}$. (e) X-ray diffraction of PANI-MWNTs and PANI-MWNT$\mathrm{Fe}_{3} \mathrm{O}_{4}$. Magnetization hysteresis of (f) MWNTs and PANI-MWNTs, (g) PANI-MWNT- $\mathrm{Fe}_{3} \mathrm{O}_{4}$. Dispersion test of nanoparticles in (h) $\mathrm{H}_{2} \mathrm{O}$ and (i) chloroform where (1) MWNTs, (2) $\mathrm{Fe}_{3} \mathrm{O}_{4}$, and (3) PANI-MWNT- $\mathrm{Fe}_{3} \mathrm{O}_{4}$

the blends (Fig. 2f-h). This is further confirmed by selective dissolution experiments (Fig. 2i and j). Generally, BT nanoparticles also have a tendency to selectively localize in the PVDF phase which was clearly demonstrated in our previous work. ${ }^{41}$ So, by tailoring the surface chemistry of BT it can be restricted in the PC phase via nucleophilic substitution reaction. SEM images showed that by controlling the dispersion doesn't affect the overall co-continuous phase morphology in the blends. Furthermore, localization of $\mathrm{BT}$ and $\mathrm{Fe}_{3} \mathrm{O}_{4}$ nanoparticles in different phases is confirmed by the selective dissolution test and EDS analysis (Fig. 2k-m). From the selective dissolution test, where we selectively etched the PC phase by chloroform, it is observed that the obtained solution is turbid indicating the presence of $\mathrm{BT}$ in the PC phase due to nucleophilic substitution reaction between PC and BT. Fig. 2m illustrates the EDS spectra of the blend without etching the phases which confirms the presence of both $\mathrm{BT}$ and $\mathrm{Fe}_{3} \mathrm{O}_{4}$ nanoparticles whereas, Fig. 2j clearly supports the fact that $\mathrm{Fe}_{3} \mathrm{O}_{4}$ nanoparticles are present only in the PVDF phase. In Fig. 2m(ii), the green color corresponds to the $\mathrm{Fe}_{3} \mathrm{O}_{4}$ nanoparticles in the PVDF phase whereas, the red color in Fig. $2 \mathrm{~m}$ (iii) corresponds to the BT nanoparticles in the PC phase. The selective localization of particles is well observed from the crystallization and melting temperature of the blend. Fig. $2 \mathrm{n}$ and o depict the crystallization temperature of neat PC/PVDF blends and the crystallization temperature of the PVDF phase was observed to be $c a .132{ }^{\circ} \mathrm{C}$. The crystallization temperature of the blends was significantly enhanced in the presence of PANI-MWNT- $\mathrm{Fe}_{3} \mathrm{O}_{4}$. This clearly indicates the preferential localization of these nanoparticles in the PVDF phase. Interestingly, the crystallization temperature of the PVDF phase was unaltered when the BT particles restricted in the PC phase. Similar observations were also obtained from the melting temperature. After incorporation of PANI-MWNT- $\mathrm{Fe}_{3} \mathrm{O}_{4}$ nanoparticles the melting temperature of PVDF increased by $8{ }^{\circ} \mathrm{C}$; however, when the BT nanoparticles were localized in the PC phase, the melting temperature almost remained unaltered. Thermal stability of the different blends was examined by TGA analysis. Fig. $2 p$ shows the TGA curves. The neat PC/PVDF blend was thermally 

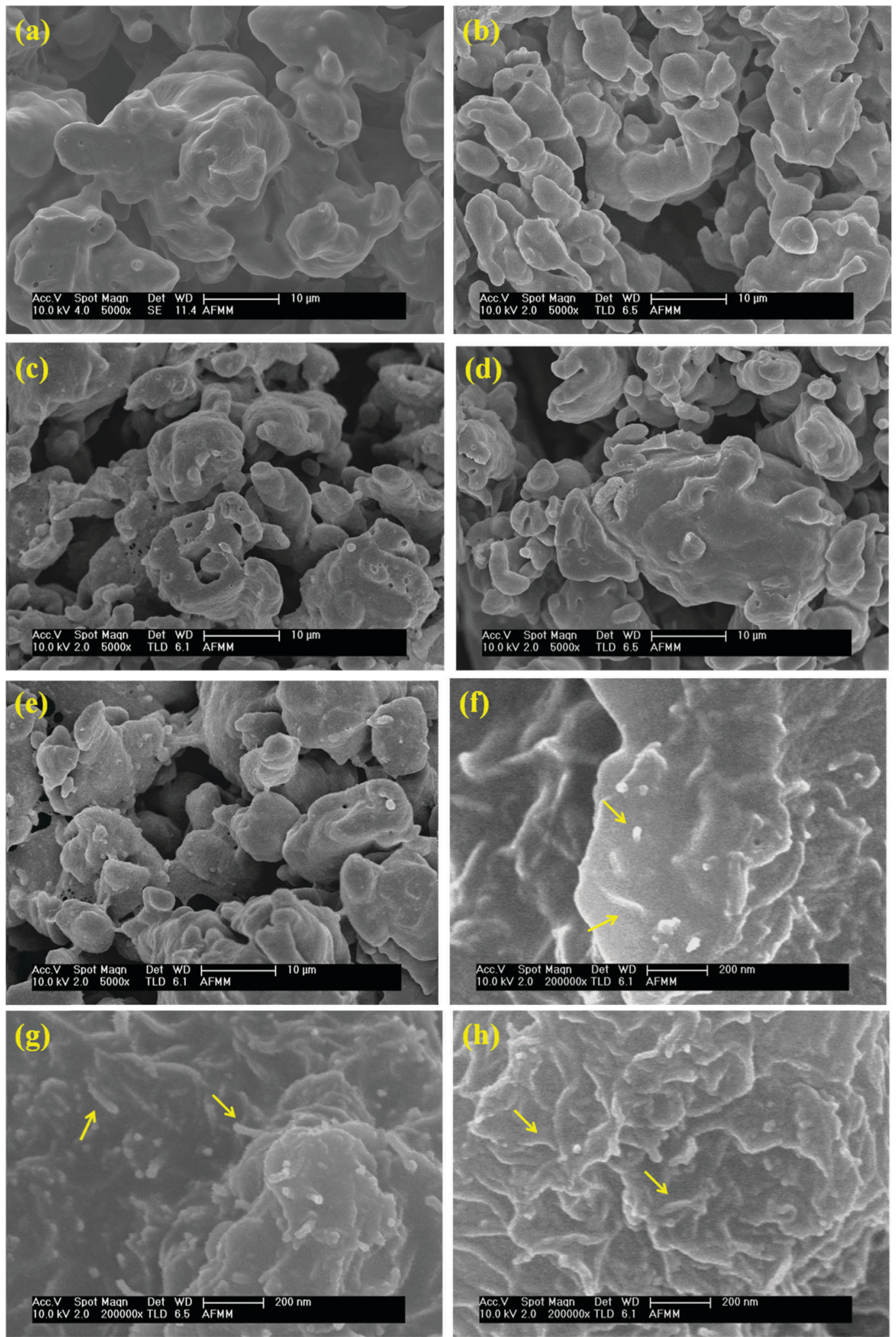

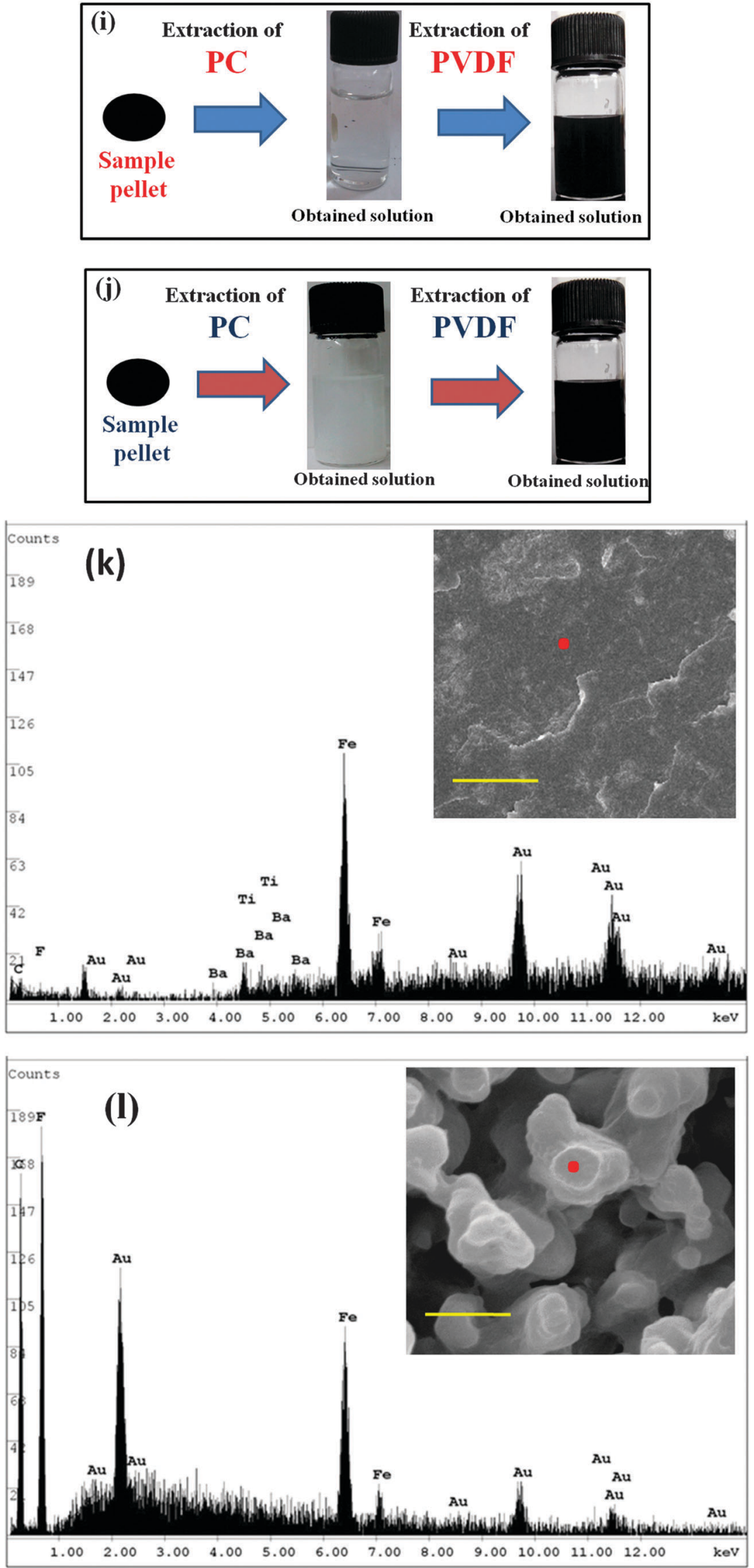
(m)

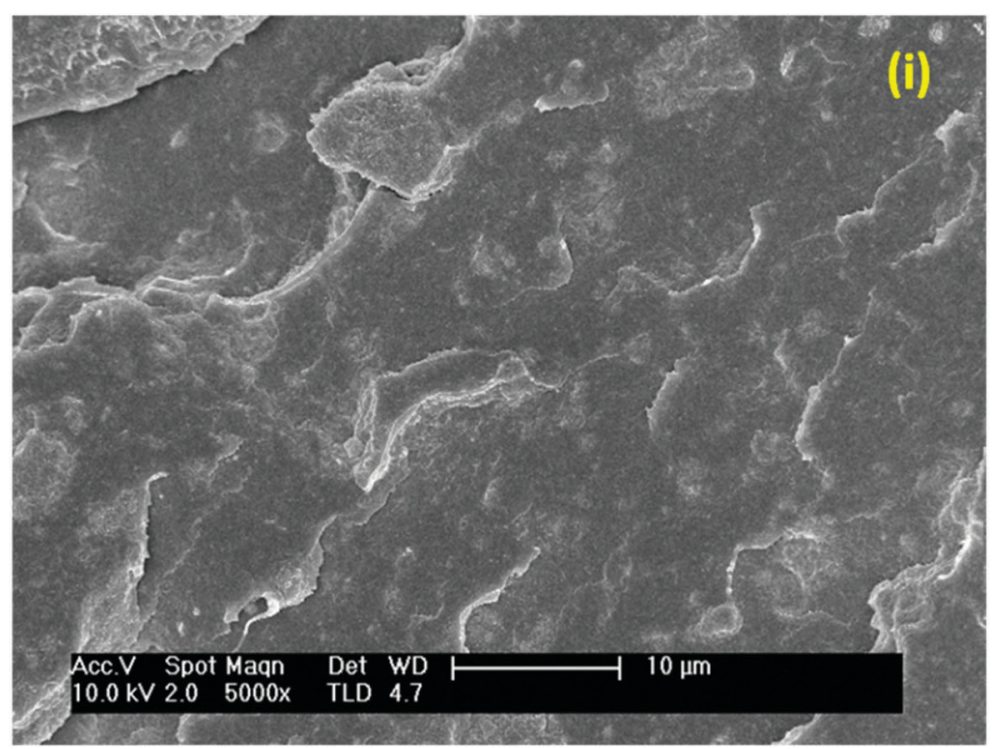

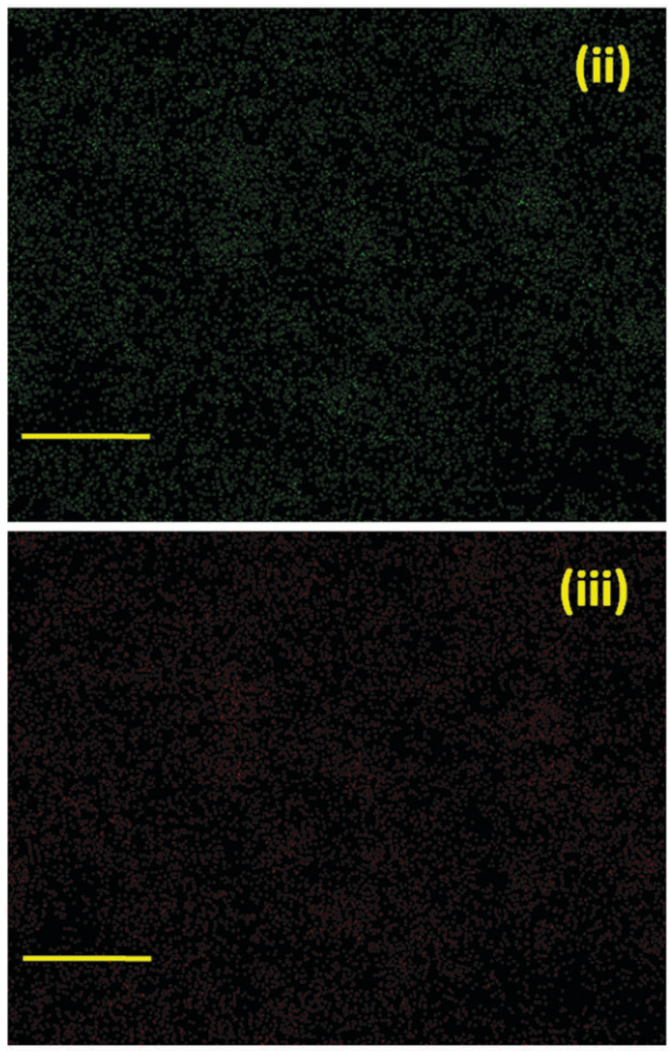
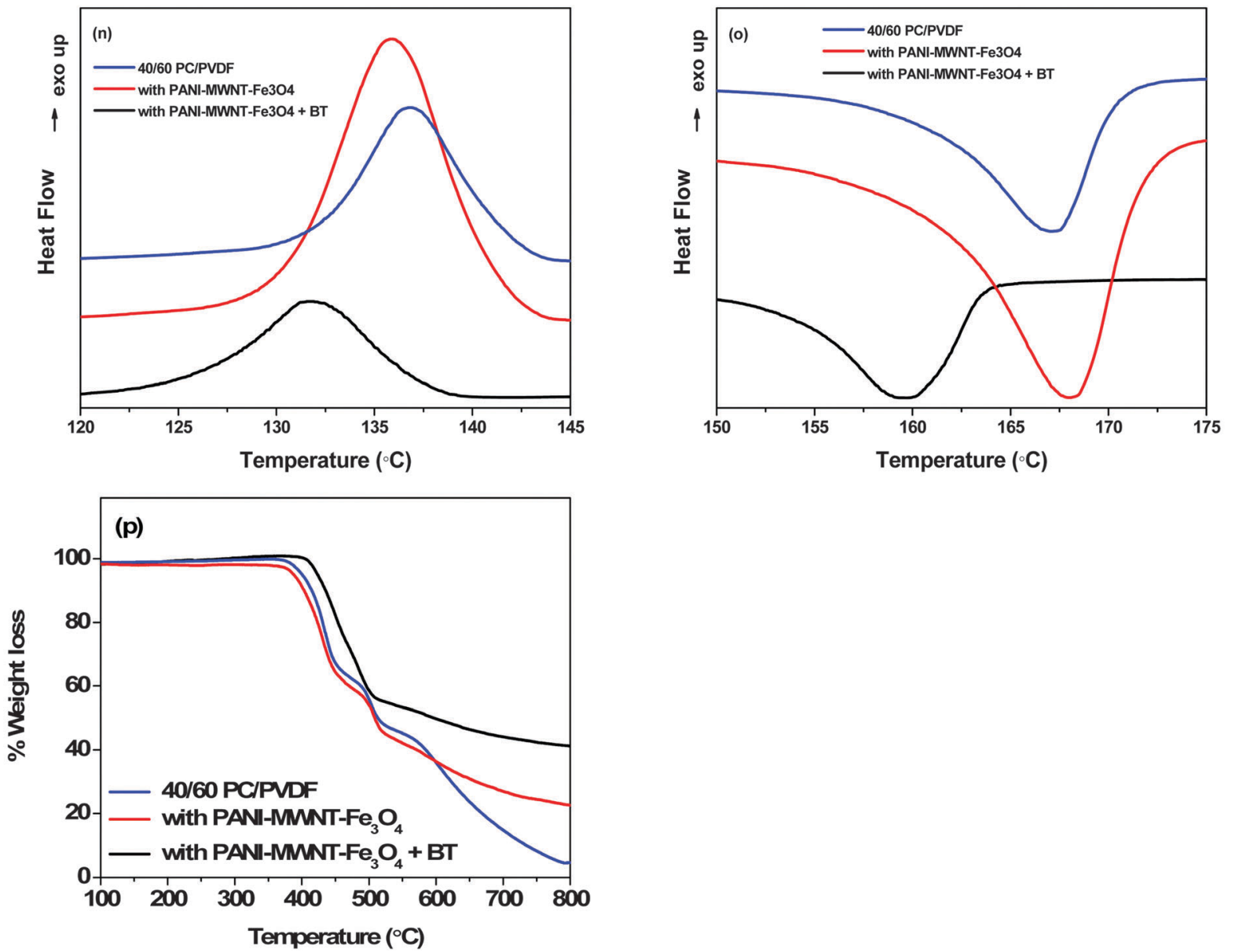


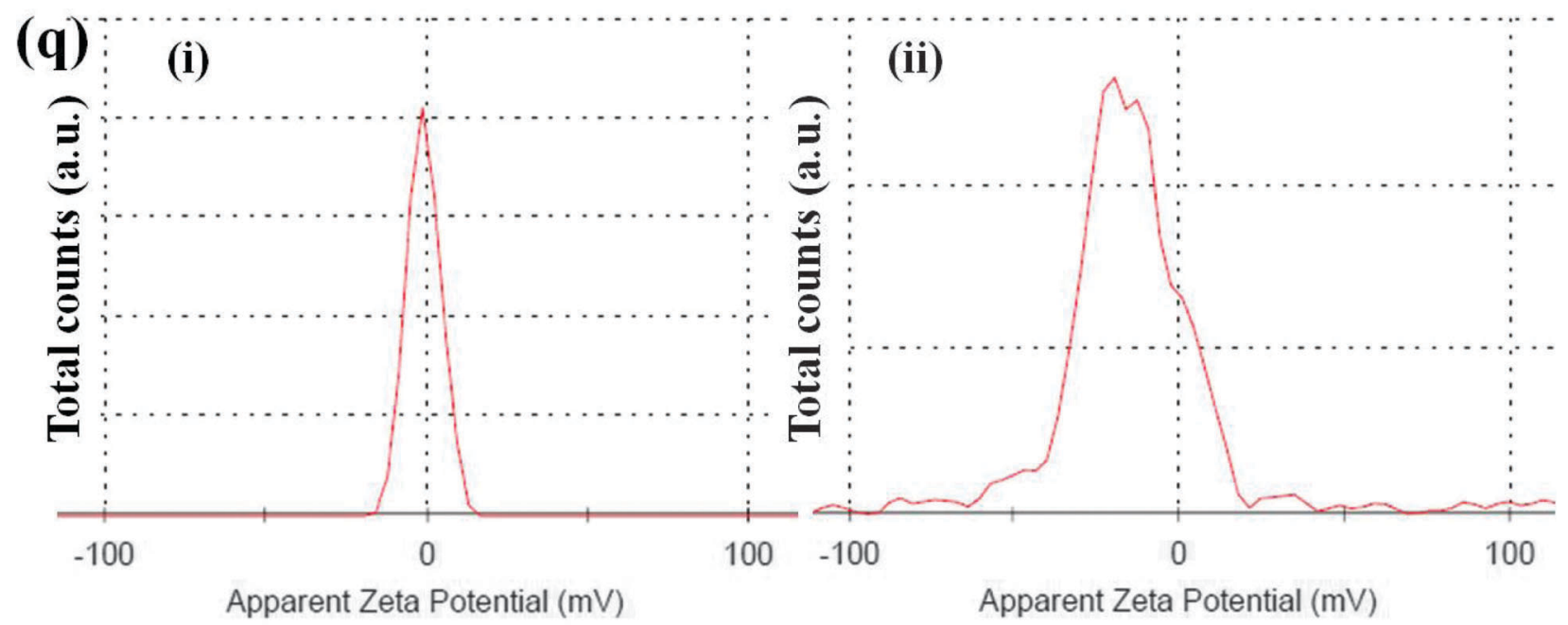

Fig. 2 Scanning electron microscopy images of (a) neat 40/60 PC/PVDF, (b) with MWNTs, (c) with PANI-MWNTs, (d) with PANI-MWNT-Fe $\mathrm{O}_{4}$ and (e) with PANI-MWNT- $\mathrm{Fe}_{3} \mathrm{O}_{4}+\mathrm{BT}$. High resolution SEM micrograph of (f) MWNT, (g) PANI-MWNT, and (h) PANI-MWNT-Fe $\mathrm{O}_{4}$ (arrows indicates the positions of MWNTs). Selective dissolution experiments where the samples are dissolved in chloroform to extract the PC phase and dissolved in DMF to extract the PVDF phase (i) with PANI-MWNT- $\mathrm{Fe}_{3} \mathrm{O}_{4}$ and (j) with PANI-MWNT-Fe $\mathrm{O}_{4}+\mathrm{BT}$. EDS of blends containing PANI-MWNT-Fe $\mathrm{O}_{4}$ in the PVDF phase and $\mathrm{BT}$ in the $\mathrm{PC}$ phase; $(\mathrm{k})$ without etching, (l) after etching the PC phase by chloroform (the inset shows the morphology of those blends, where

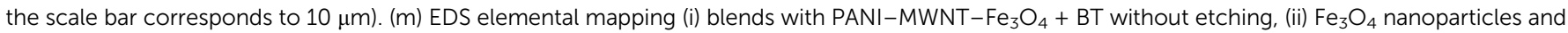
(iii) BT nanoparticles (scale bar corresponds to $5 \mu \mathrm{m}$ ). DSC thermal analysis of various blends at (n) crystallization temperature, and (o) melting temperature; (p) TGA of different blends, and (q) apparent zeta potentials of (i) BT and (ii) PANI-MWNT- $\mathrm{Fe}_{3} \mathrm{O}_{4}$.

stable until $370{ }^{\circ} \mathrm{C}$. However, it is very interesting to note that the nanoparticles enhanced the thermal stability by $c a .30{ }^{\circ} \mathrm{C}$. The zeta potential for the various nanoparticles was measured and the results are shown in Fig. 2q(i and ii). The apparent zeta potential for BT in water is $-1.12 \mathrm{mV}$ and for PANI-MWNT$\mathrm{Fe}_{3} \mathrm{O}_{4}$ is $-18.6 \mathrm{mV}$. This signifies that the BT nanoparticles coagulates in water whereas, $\mathrm{PANI}-\mathrm{MWNT}-\mathrm{Fe}_{3} \mathrm{O}_{4}$ has incipient instability in water.

\section{Interconnected network like structure of MWNT}

Continuity of the conducting network is the prime requisite for carrying mobile charge in any system. In blends, electrical conductivity can be tailored depending on the aspect ratio, amount, surface treatment, and distribution of the conducting fillers, which play an essential role in attaining the percolation threshold. ${ }^{42-44}$ Selectively dispersed MWNTs in the PVDF phase show an increasing order of electrical conductivity with increasing concentration of MWNTs from 1-3 wt\% where the percolation threshold is between $0-1 \mathrm{wt} \%$. The increasing concentration of MWNTs allows the formation of a 3-D conducting network, which further promotes the charge transport properties of the blends. After inclusion of PANI-MWNTs in the blend, the bulk conductivity increased by 2 orders of magnitude. However, on adding PANI-MWNT- $\mathrm{Fe}_{3} \mathrm{O}_{4}$ the AC electrical conductivity decreased due to the direct contact of $\mathrm{Fe}_{3} \mathrm{O}_{4}$ nanoparticles with the MWNTs which eventually impedes the flow of electrons. Interestingly, the dielectric permittivity increases after addition of PANI-MWNTs and PANI-MWNT- $\mathrm{Fe}_{3} \mathrm{O}_{4}$ in the blends due to the mismatching impedance of the entities. In our previous study, ${ }^{41}$ we showed that PVDF is the more favoured phase for selective localization of BT nanoparticles. We also demonstrated that such localization can affect the bulk electrical conductivity in the blends. Here by adopting a compartmentalized approach, we restrict the BT particles in the PC phase by nucleophilic substitution reaction so that the formation of the conducting network inside the PVDF phase is unaltered. However, the dielectric permittivity of the blends increased significantly due to the higher dielectric permittivity of the BT nanoparticles (Fig. 3c).

\section{Attenuation of EM radiation through a compartmentalized approach}

Controlled microstructural heterogeneities in the composites are the key requisites for absorption of microwave radiation on the macroscale. So, the incident EM waves interact with the microscopic boundaries in the composites resulting in attenuation of the waves. ${ }^{45,46}$

As we discussed earlier the total EM shield effectiveness $\left(\mathrm{SE}_{\mathrm{T}}\right)$ is the combination of shielding by absorption $\left(\mathrm{SE}_{\mathrm{A}}\right)$; by reflection $\left(\mathrm{SE}_{\mathrm{R}}\right)$ and by multiple reflection $\left(\mathrm{SE}_{\mathrm{MR}}\right) \cdot{ }^{47,48}$ But due to the increasing absorption of reflected waves from the internal surface, the multiple reflections can be ignored when the shield thickness is greater than the skin depth. In this context $\mathrm{SE}_{\mathrm{T}}$ can be expressed as,

$$
\mathrm{SE}_{\mathrm{T}}=\mathrm{SE}_{\mathrm{A}}+\mathrm{SE}_{\mathrm{R}}
$$

From the vector network analyzer (VNA), the $\mathrm{SE}_{\mathrm{T}}$ can be estimated by the following relation through scattering parameters where the scattering parameters are the representatives of reflected, absorbed and transmitted power.

$$
\mathrm{SE}_{\mathrm{T}}(\mathrm{dB})=10 \log \frac{1}{\left|S_{12}\right|^{2}}=10 \log \frac{1}{\left|S_{21}\right|^{2}}
$$



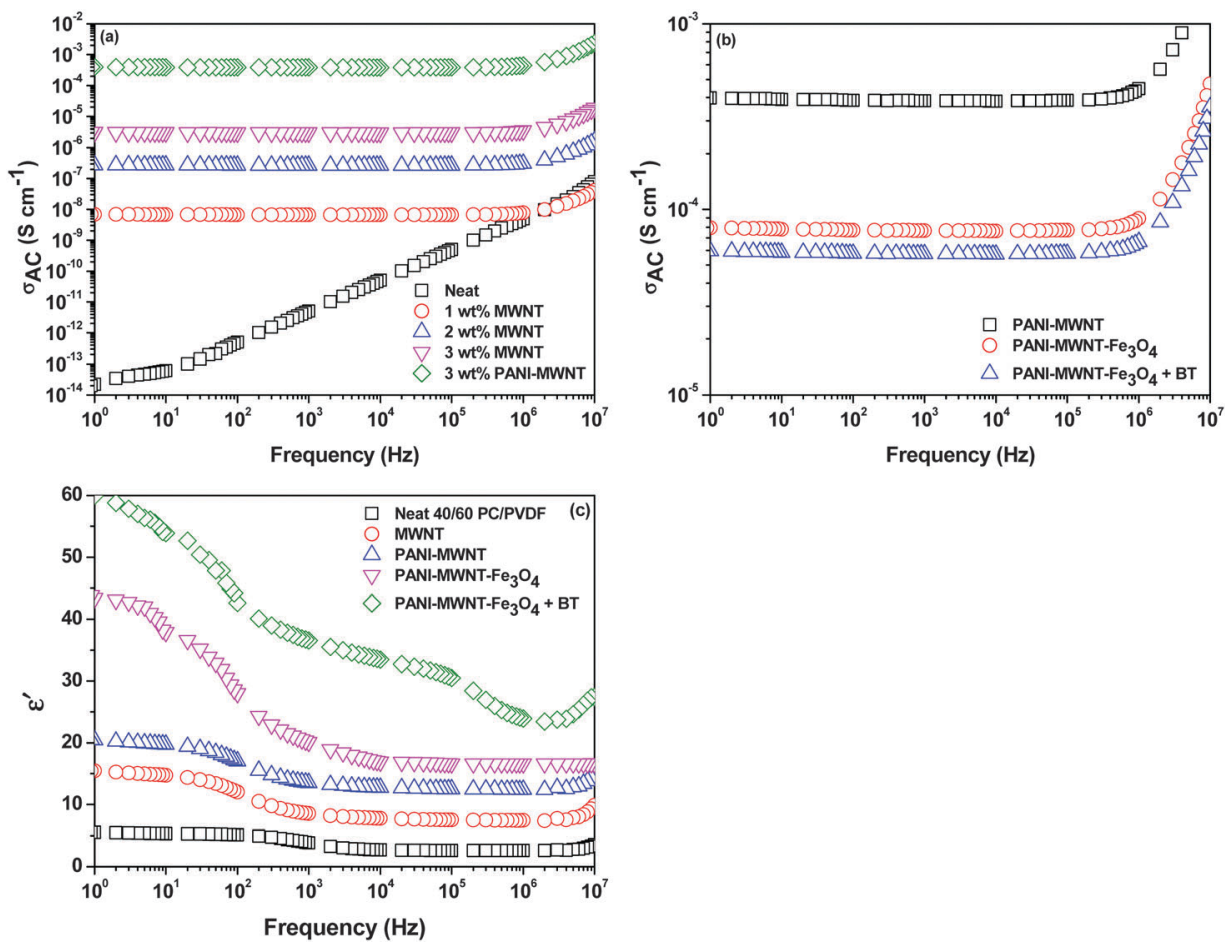

Fig. 3 Frequency dependent AC electrical conductivity plot at room temperature of various blends (a) and (b). Frequency dependent dielectric constants of various blends (c).

where $S_{12}$ is a reverse transmission coefficient whereas $S_{21}$ is a forward transmission coefficient. With the help of these coefficients we can express the total reflection and absorption by the following equations,

$$
\begin{gathered}
\mathrm{SE}_{\mathrm{R}}=10 \log _{10}\left(1 /\left(1-{S_{11}}^{2}\right)\right) \\
\mathrm{SE}_{\mathrm{A}}=10 \log _{10}\left(\left(1-{S_{11}}^{2}\right) / S_{12}{ }^{2}\right)
\end{gathered}
$$

where $S_{11}$ is a forward reflection coefficient. Another important parameter, the intensity of penetration, i.e. skin depth $(\delta)$, can be explained by the following equation,

$$
\delta=1 / \sqrt{\pi f \mu \sigma}
$$

where $f$ is the frequency in $\mathrm{Hz}$, permittivity is represented by $\mu$ and the conductivity of the blend is $\sigma$. The skin depth is also related to shielding by absorption as

$$
\mathrm{SE}_{\mathrm{A}}=-8.68(t / \delta)
$$

where $t$ is the sample thickness measured in mm. All scattering parameters were measured here in the frequency region; $\mathrm{X}$ and Ku-band frequencies.

From the EMI theory it is well understood that in order to attenuate EM radiation, materials should have sufficient electrical conductivity. In the case of polymer nanocomposites, the connectivity of the conducting nanoparticles is essential for achieving bulk electrical conductivity. $\mathrm{A} \mathrm{SE}_{\mathrm{T}}$ is $-10 \mathrm{~dB}$ observed at $18 \mathrm{GHz}$ frequency was obtained for the PC/PVDF blend with $1 \mathrm{wt} \%$ MWNT (Fig. 4a) while the neat PC/PVDF blend is transparent to EM radiation. Furthermore, it is observed that $\mathrm{SE}_{\mathrm{T}}$ is increased with increasing concentration of MWNTs. In the case of MWNT filled blends, the dielectric losses are higher and the attenuation is due to wave reflection rather than absorption. So, concentration dependent $\mathrm{SE}_{\mathrm{T}}$ is observed beyond the percolation threshold (Fig. 4a). The shielding mechanism is dominated by reflection when MWNTs alone are considered due to their lower dielectric loss and poor magnetic properties. But heterogeneous inclusion can change the shielding mechanism from reflection to absorption by introducing high dielectric or high magnetic loss parameters which are represented by complex (relative) permittivity $\left(\varepsilon_{\mathrm{r}}\right)$ and complex (relative) permeability $\left(\mu_{\mathrm{r}}\right)$, respectively. ${ }^{49-51}$ Generally, when an EM wave interacts with such heterogeneous fields, the resulting local field variation can have a strong effect on the energy of absorption. Now theoretically, shielding by absorption or reflection can be varied by these equations: $\mathrm{SE}_{\mathrm{A}}=8.68 t \sqrt{\pi f \sigma \mu}$ and $\mathrm{SE}_{\mathrm{R}}=39.5+10 \log (\sigma / 2 \pi f \mu)$, whereas $\mu=\mu_{0} \mu_{\mathrm{r}}$ and $\sigma=2 \pi \varepsilon_{0} \varepsilon^{\prime \prime}$. So, enhanced absorption is observed with higher values of $\mu_{\mathrm{r}}$ and $\varepsilon_{\mathrm{r}}$ where $\mu_{\mathrm{r}}=\mu^{\prime}-j \mu^{\prime \prime}$ and $\varepsilon_{\mathrm{r}}=\varepsilon^{\prime}-j \varepsilon^{\prime \prime}$.

In situ polymerized PANI-MWNTs increase the total shielding effectiveness (Fig. 4b) due to their higher conductivity and higher complex relative permittivity values than pristine MWNTs. The accumulation of charge at the interface leads to interfacial polarization. As $\varepsilon_{\mathrm{r}}$ is a measure of polarizability in the material, PANI-MWNTs possess higher complex permittivity than only MWNTs. ${ }^{52}$ The increase in complex relative permittivity presumably increased the shielding by absorption (Fig. 4c-f) as absorption depends primarily on the product of $\varepsilon$ and $\mu$. By introducing PANI-MWNT- $\mathrm{Fe}_{3} \mathrm{O}_{4}$ in the blends both the complex relative 

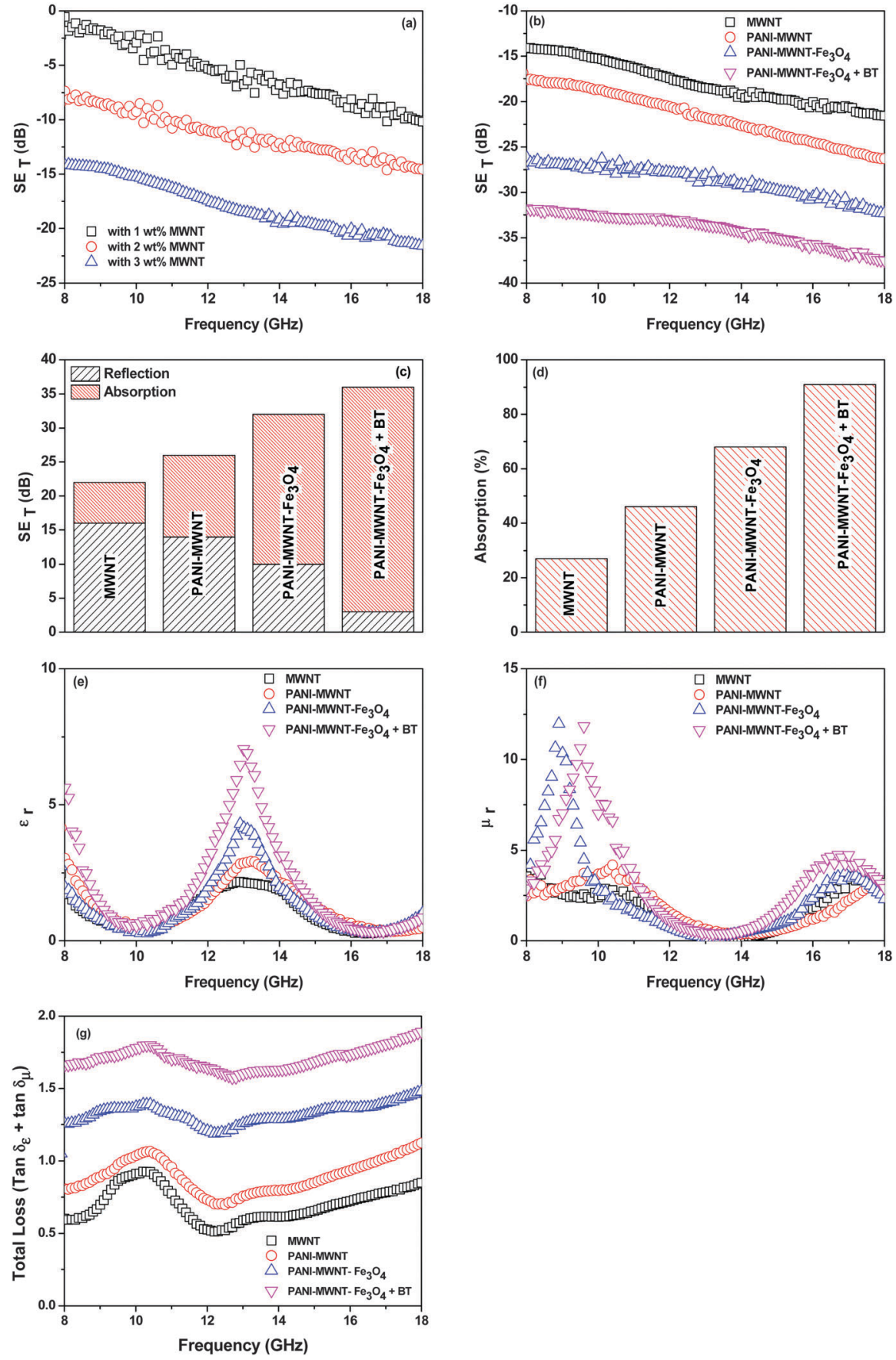

Fig. 4 Frequency variation total shielding effectiveness of (a) blends with MWNTs and (b) blends with different nanoparticles. (c) Absorption and reflection components of blends at a constant frequency of $18 \mathrm{GHz}$. (d) \% Absorption of blends at a constant frequency of $18 \mathrm{GHz}$. (e) Relative complex permittivity of various blends as a function of frequency. (f) Relative complex permeability of various blends as a function of frequency. (g) Tangent loss as a function of frequency of various blends.

permeability and permittivity increased significantly resulting in more effective shielding by absorption. ${ }^{53-56}$ Further, from EM theory it is well observed that enhanced dielectric and magnetic tangent losses also improve the EM absorption properties. So, for better comparison of the EM absorption properties of various blends we calculated the consolidated loss tangent values of various blends with frequency variation. Fig. $4 \mathrm{~g}$ depicts that the blend with PANI-MWNT- $\mathrm{Fe}_{3} \mathrm{O}_{4}+\mathrm{BT}$ exhibited the highest tangent loss value compared to any other blend thus accounting for the enhancement in absorption efficiency. It is worth noting that $M_{\mathrm{S}}$ has increased significantly from $0.15 \mathrm{emu} \mathrm{g}^{-1}$ for PANI-MWNT to $28 \mathrm{emu} \mathrm{g}^{-1}$ for PANI-MWNT-Fe ${ }_{3} \mathrm{O}_{4}$ which begins to suggest that increased $M_{\mathrm{S}}$ eventually leads to enhanced $\mu$ as observed from the following relation, ${ }^{57}$

$$
\mu_{\mathrm{i}}=M_{\mathrm{s}}^{2} /\left(a K H_{\mathrm{c}} M_{\mathrm{s}}+b \lambda \xi\right)
$$


Table 1 Shielding parameters of various 40/60 PC/PVDF blends at $18 \mathrm{GHz}$ frequency

\begin{tabular}{llll}
\hline Composition & $\mathrm{SE}_{\mathrm{T}}(\mathrm{dB})$ & $\mathrm{SE}_{\mathrm{A}}(\mathrm{dB})$ & $\mathrm{SE}_{\mathrm{R}}(\mathrm{dB})$ \\
\hline MWNT & -22 & -6 & -16 \\
PANI-MWNT & -26 & -12 & -14 \\
PANI-MWNT- $\mathrm{Fe}_{3} \mathrm{O}_{4}$ & -32 & -22 & -10 \\
PANI-MWNT- $\mathrm{Fe}_{3} \mathrm{O}_{4}+\mathrm{BT}$ & -37 & -34 & -3
\end{tabular}

where constants $a$ and $b$ are determined by the material composition, the magneto restriction constant is $\lambda$, the elastic strain parameter of the crystal is $\xi$ and $K$ is the proportionality coefficient. So, increasing the permeability results in higher total shielding by absorption. Interestingly, the relative complex permittivity enhanced significantly in the presence of BT nanoparticles in the blends. As discussed earlier employing a compartmentalized approach wherein BT nanoparticles are preferentially localized in the PC phase and PANI-MWNT- $\mathrm{Fe}_{3} \mathrm{O}_{4}$ in the PVDF phase resulted in a synergistic enhancement in both $\mu_{\mathrm{r}}$ and $\varepsilon_{\mathrm{r}}$. This ultimately resulted in a high $\mathrm{SE}_{\mathrm{T}}$ of $c a .-37 \mathrm{~dB}$ at $18 \mathrm{GHz}$, which indicates ca. $92 \%$ shielding by absorption. This clearly demonstrates that adopting such a compartmentalized approach can result in effective shielding by absorption (Table 1).
Further $R_{\mathrm{L}}$ also can be calculated by the line theory. In general the reflection loss parameters also directly related to the complex relative parameters by this equation,

$$
\begin{gathered}
R_{\mathrm{L}}=20 \log \left(\left|Z_{\text {in }}-1\right| /\left|Z_{\text {in }}+1\right|\right) \\
Z_{\text {in }}=\left(\mu_{\mathrm{r}} / \varepsilon_{\mathrm{r}}\right)^{1 / 2} \tanh \left\{j \frac{2 \pi}{c}\left(\mu_{\mathrm{r}} / \varepsilon_{\mathrm{r}}\right)^{1 / 2} f t\right\}
\end{gathered}
$$

where the sample thickness is represented by $t$ and the velocity of light is represented by $c$. In the case of $R_{\mathrm{L}}$ as a function of frequency, the depth is responsible for absorption of EM radiation or minimal reflection. Fig. 5 a represents the $R_{\mathrm{L}}$ of various blends. Multiple dips are observed in the case of all the blends in the entire frequency range. These are representatives of maximum absorption at respective frequencies. Polarization or multiple reflections are the source of reflection loss when only MWNTs are considered and the minimum $R_{\mathrm{L}}$ is $c a .-33 \mathrm{~dB}$ at $12 \mathrm{GHz}$ frequency. Higher dielectric relaxation loss is due to the virtual charge accumulation in the interfacial region in heterogeneous dielectrics which also increases the complex permittivity and leads to higher reflection loss in the case of PANI-MWNT filled blends. The minimum $R_{\mathrm{L}}$ is $c a$. $-40 \mathrm{~dB}$ at a $16 \mathrm{GHz}$ frequency. PANI-MWNT- $\mathrm{Fe}_{3} \mathrm{O}_{4}$ containing blends exhibited excellent $R_{\mathrm{L}}$ due
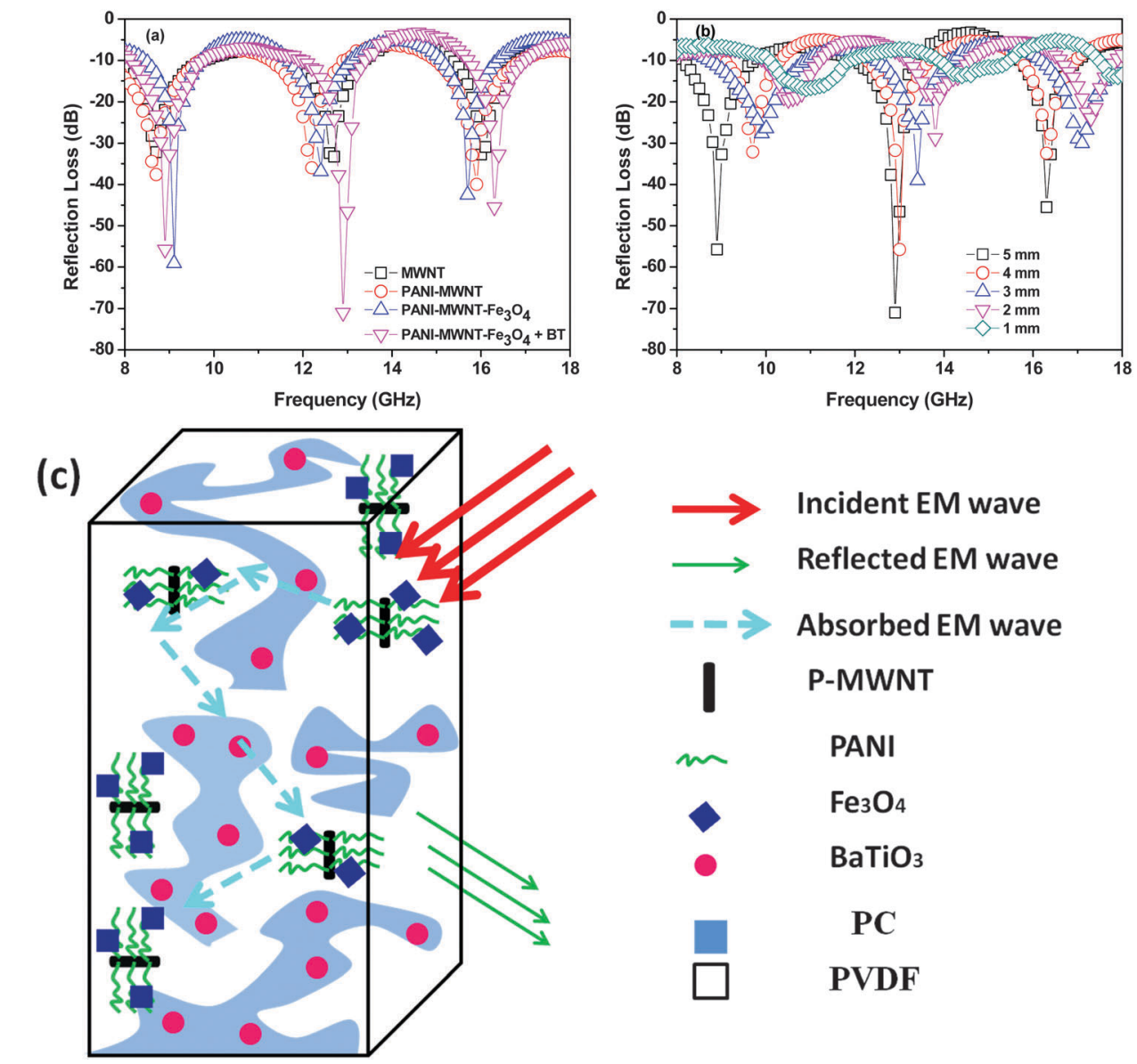

Fig. 5 Reflection loss as a function of frequency (a), and thickness (b); a cartoon illustrating the mechanism of shielding in the blends containing PANIMWNT- $\mathrm{Fe}_{3} \mathrm{O}_{4}$ in the PVDF phase and $\mathrm{BT}$ in the PC phase (c). 
to the involvement of very high magnetic lossy materials. Interestingly, by adopting the compartmentalized approach the contribution from both dielectric and magnetic lossy nanoparticles exhibited an outstanding minimum $R_{\mathrm{L}}$ of $c a .-71 \mathrm{~dB}$ at $12.9 \mathrm{GHz}$ frequency. Fig. 5a begins to suggest that the complex relative permittivity and permeability of the blends can be tuned to tailor the shielding efficiency. ${ }^{58,59}$ The effect of higher permeability is evident in the lower frequency region whereas the effect of higher permittivity is observed in the higher frequency region (Fig. 5a). Furthermore, the shield thickness has a significant effect on the EM attenuation. Hence, the reflection loss was measured for varying shield thickness and is depicted in Fig. 5b. It is observed that frequencies corresponding to the minimum reflection loss shift from higher to lower with increasing specimen thickness, which is concomitant with quarter-wavelength attenuation..$^{53,60-62} \mathrm{Fig}$. $5 \mathrm{c}$ illustrates the shielding mechanism of the blends by absorption wherein PANI-MWNT- $\mathrm{Fe}_{3} \mathrm{O}_{4}$ is in the PVDF phase and the BT nanoparticles are in the PC phase.

The $\mathrm{SE}_{\mathrm{T}}$ is also observed to scale with increasing sample thickness ${ }^{63}$ (Fig. 6a and Table 2). This result clearly indicates that increasing the shield thickness eventually formed a more continuous conductive or magnetic network, which enhanced the overall shielding. Additionally, the increasing sample thickness also enhances multiple reflection inside the sample. Interestingly, the skin depth of the sample can also be tailored
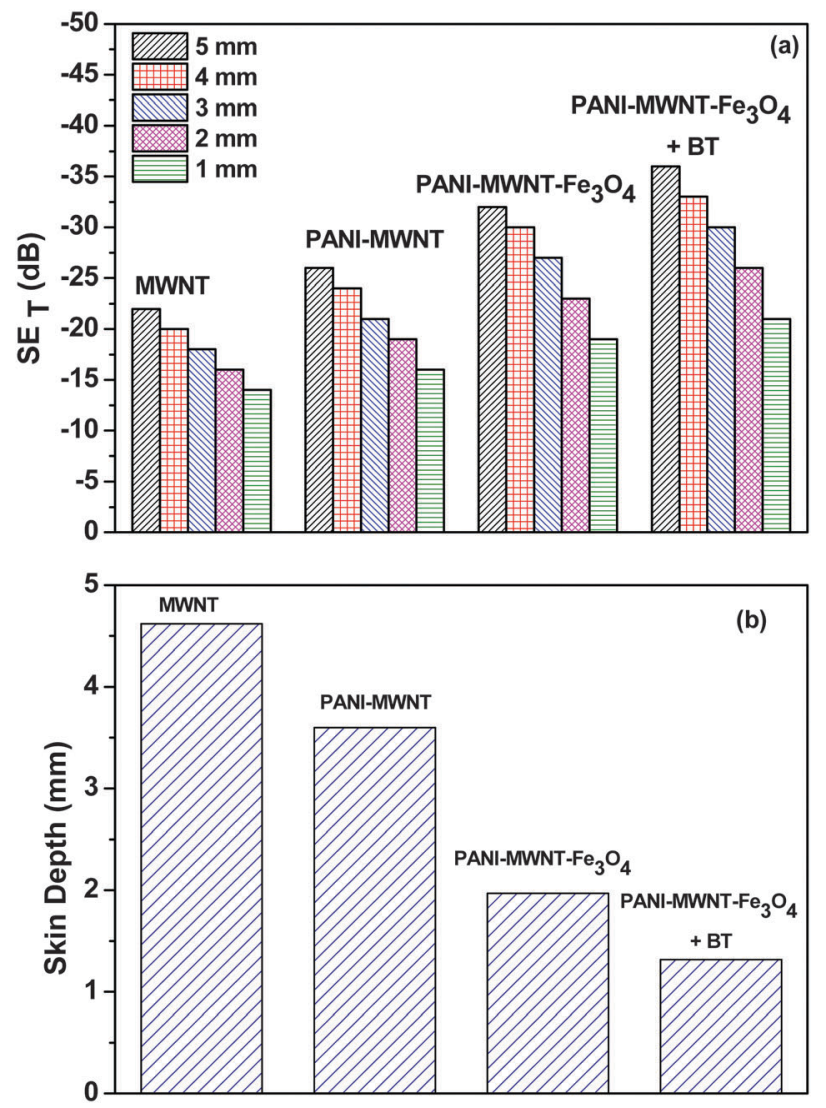

Fig. 6 (a) $\mathrm{SE}_{\mathrm{T}}$ of various blends as a function of thickness, and (b) the skin depth of various blends.
Table 2 Thickness dependent $\mathrm{SE}_{\mathrm{T}}$ of different samples at $18 \mathrm{GHz}$ frequency

\begin{tabular}{lllllr}
\hline Compositions & $\begin{array}{l}5 \mathrm{~mm} \\
(\mathrm{~dB})\end{array}$ & $\begin{array}{l}4(\mathrm{~mm}) \\
(\mathrm{dB})\end{array}$ & $\begin{array}{l}3(\mathrm{~mm}) \\
(\mathrm{dB})\end{array}$ & $\begin{array}{l}2(\mathrm{~mm}) \\
(\mathrm{dB})\end{array}$ & $\begin{array}{l}1(\mathrm{~mm}) \\
(\mathrm{dB})\end{array}$ \\
\hline MWNT & -22 & -20 & -18 & -16 & -14 \\
PANI-MWNT & -26 & -24 & -21 & -19 & 16 \\
PANI-MWNT- $\mathrm{Fe}_{3} \mathrm{O}_{4}$ & -32 & -30 & -27 & -23 & -19 \\
PANI-MWNT- $\mathrm{Fe}_{3} \mathrm{O}_{4}$ & -37 & -33 & -30 & -26 & -21 \\
$+\mathrm{BT}$ & & & & & \\
\hline
\end{tabular}

by addition of various filler particles. The addition of magnetic or dielectric lossy particles drastically decreases the overall skin depth of the blend (Fig. 6b). These results clearly suggest that a combination of conducting, dielectric and magnetic particles can block the incoming EM radiation efficiently and more importantly in thinner shields. This is very important in the context of designing lightweight and flexible shields.

\section{Conclusions}

In this work, we have clearly demonstrated that adopting a compartmentalized approach, wherein nanoscopic particles with different characteristics are localized in different phases of an immiscible polymer blend, can yield outstanding microwave absorption. This was designed using a co-continuous PC/PVDF blend wherein PANI modified MWNTs and $\mathrm{Fe}_{3} \mathrm{O}_{4}$ were selectively localized in PVDF, and the BT nanoparticles were surface modified to restrict in PC via nucleophilic substitution reaction. This approach manifested in an excellent $R_{\mathrm{L}}$ of $c a$. $-71 \mathrm{~dB}$ at 12.9 GHz frequency. It is now understood that the in situ PANIMWNT not only enhances the charge transport efficiency in the blend but also increases the shielding by absorption. In addition, by this approach $c a$. $90 \%$ of the EM radiation can be blocked by absorption through a synergistic combination of high relative permittivity (from BT and PANI-MWNT- $\mathrm{Fe}_{3} \mathrm{O}_{4}$ ), high relative permeability (PANI-MWNT- $\mathrm{Fe}_{3} \mathrm{O}_{4}$ ) and high conductivity. Hence, this approach clearly demonstrates that ordered arrangement of nanoparticles in the blends can be used to design an efficient microwave absorber.

\section{Acknowledgements}

The authors gratefully acknowledge the financial support from DST (India).

\section{References}

1 Y. Yang, M. C. Gupta, K. L. Dudley and R. W. Lawrence, Nano Lett., 2005, 5, 2131-2134.

2 J.-M. Thomassin, C. Pagnoulle, L. Bednarz, I. Huynen, R. Jerome and C. Detrembleur, J. Mater. Chem., 2008, 18, 792-796.

3 H. Wang, G. Wang, W. Li, Q. Wang, W. Wei, Z. Jiang and S. Zhang, J. Mater. Chem., 2012, 22, 21232-21237.

4 A. Ameli, M. Nofar, S. Wang and C. B. Park, ACS Appl. Mater. Interfaces, 2014, 6, 11091-11100. 
5 A. Fletcher, M. C. Gupta, K. L. Dudley and E. Vedeler, Compos. Sci. Technol., 2010, 70, 953-958.

6 H. Kim, K. Kim, C. Lee, J. Joo, S. Cho, H. Yoon, D. Pejaković, J.-W. Yoo and A. Epstein, Appl. Phys. Lett., 2004, 84, 589-591.

7 N. Li, Y. Huang, F. Du, X. He, X. Lin, H. Gao, Y. Ma, F. Li, Y. Chen and P. C. Eklund, Nano Lett., 2006, 6, 1141-1145.

8 H.-B. Zhang, Q. Yan, W.-G. Zheng, Z. He and Z.-Z. Yu, ACS Appl. Mater. Interfaces, 2011, 3, 918-924.

9 M. H. Al-Saleh and U. Sundararaj, Carbon, 2009, 47, 1738-1746.

10 M. H. Al-Saleh and U. Sundararaj, Carbon, 2009, 47, 2-22.

11 M. Arjmand, M. Mahmoodi, G. A. Gelves, S. Park and U. Sundararaj, Carbon, 2011, 49, 3430-3440.

12 S. Maiti, N. K. Shrivastava, S. Suin and B. Khatua, ACS Appl. Mater. Interfaces, 2013, 5, 4712-4724.

13 D. Chen, G.-S. Wang, S. He, J. Liu, L. Guo and M.-S. Cao, J. Mater. Chem. A, 2013, 1, 5996-6003.

14 P. Saini and M. Arora, J. Mater. Chem. A, 2013, 1, 8926-8934.

15 R. Qiang, Y. Du, H. Zhao, Y. Wang, C. Tian, Z. Li, X. Han and P. Xu, J. Mater. Chem. A, 2015, 3, 13426-13434.

16 S. P. Pawar, D. A. Marathe, K. Pattabhi and S. Bose, J. Mater. Chem. A, 2015, 3, 656-669.

17 G. P. Kar, S. Biswas, R. Rohini and S. Bose, J. Mater. Chem. A, 2015, 3, 7974-7985.

18 P. Saini, V. Choudhary, N. Vijayan and R. Kotnala, J. Phys. Chem. C, 2012, 116, 13403-13412.

19 J. Wei, S. Zhang, X. Liu, J. Qian, J. Hua, X. Li and Q. Zhuang, J. Mater. Chem. A, 2015, 3, 8205-8214.

20 P. Zhao, C. Liang, X. Gong, R. Gao, J. Liu, M. Wang and R. Che, Nanoscale, 2013, 5, 8022-8028.

21 T. K. Gupta, B. P. Singh, V. N. Singh, S. Teotia, A. P. Singh, I. Elizabeth, S. R. Dhakate, S. Dhawan and R. Mathur, J. Mater. Chem. A, 2014, 2, 4256-4263.

22 K. Hayashida and Y. Matsuoka, Carbon, 2015, 85, 363-371.

23 P. Xavier and S. Bose, RSC Adv., 2014, 4, 55341-55348.

24 C. Yang, H. Wei, L. Guan, J. Guo, Y. Wang, X. Yan, X. Zhang, S. Wei and Z. Guo, J. Mater. Chem. A, 2015, 3, 14929-14941.

25 M. Mahmoodi, M. Arjmand, U. Sundararaj and S. Park, Carbon, 2012, 50, 1455-1464.

26 M. Chen, L. Zhang, S. Duan, S. Jing, H. Jiang, M. Luo and C. Li, Nanoscale, 2014, 6, 3796-3803.

27 V. Bhingardive, M. Sharma, S. Suwas, G. Madras and S. Bose, RSC Adv., 2015, 5, 35909-35916.

28 S. Maiti, S. Suin, N. K. Shrivastava and B. Khatua, RSC Adv., 2014, 4, 7979-7990.

29 G. P. Kar, S. Biswas and S. Bose, Phys. Chem. Chem. Phys., 2015, 17, 14856-14865.

30 N. K. Shrivastava, S. Suin, S. Maiti and B. B. Khatua, Ind. Eng. Chem. Res., 2013, 52, 2858-2868.

31 S. P. Pawar, S. Kumar, A. Misra, S. Deshmukh, K. Chatterjee and S. Bose, RSC Adv., 2015, 5, 17716-17725.

32 S. Biswas, G. P. Kar and S. Bose, J. Mater. Chem. A, 2015, 3, 12413-12426.
33 T. K. Gupta, B. P. Singh, R. B. Mathur and S. R. Dhakate, Nanoscale, 2014, 6, 842-851.

34 P. Sambyal, A. P. Singh, M. Verma, M. Farukh, B. P. Singh and S. K. Dhawan, RSC Adv., 2014, 4, 12614-12624.

35 P. Saini, M. Arora, G. Gupta, B. K. Gupta, V. N. Singh and V. Choudhary, Nanoscale, 2013, 5, 4330-4336.

36 P. Saini, V. Choudhary, B. Singh, R. Mathur and S. Dhawan, Mater. Chem. Phys., 2009, 113, 919-926.

37 D. A. Makeiff and T. Huber, Synth. Met., 2006, 156, 497-505.

38 W. Li, T. Qiu, L. Wang, S. Ren, J. Zhang, L. He and X. Li, ACS Appl. Mater. Interfaces, 2013, 5, 883-891.

39 P. Saini, V. Choudhary, B. Singh, R. Mathur and S. Dhawan, Synth. Met., 2011, 161, 1522-1526.

40 P. Saini, Fundamentals of Conjugated Polymer Blends, Copolymers and Composites: Synthesis, Properties, and Applications, 2015, p. 451 .

41 S. Biswas, G. P. Kar and S. Bose, Nanoscale, 2015, 7, 11334-11351.

42 P. V. Kodgire, A. R. Bhattacharyya, S. Bose, N. Gupta, A. R. Kulkarni and A. Misra, Chem. Phys. Lett., 2006, 432, 480-485.

43 S. Bose, A. R. Bhattacharyya, A. R. Kulkarni and P. Pötschke, Compos. Sci. Technol., 2009, 69, 365-372.

44 T. K. Gupta, B. P. Singh, S. R. Dhakate, V. N. Singh and R. B. Mathur, J. Mater. Chem. A, 2013, 1, 9138-9149.

45 F. Ren, H. Yu, L. Wang, M. Saleem, Z. Tian and P. Ren, RSC Adv., 2014, 4, 14419-14431.

46 S. Pande, A. Chaudhary, D. Patel, B. P. Singh and R. B. Mathur, RSC Adv., 2014, 4, 13839-13849.

47 H. Hekmatara, M. Seifi, K. Forooraghi and S. Mirzaee, Phys. Chem. Chem. Phys., 2014, 16, 24069-24075.

48 R. Kumar, S. R. Dhakate, T. Gupta, P. Saini, B. P. Singh and R. B. Mathur, J. Mater. Chem. A, 2013, 1, 5727-5735.

49 A. Kumar, A. P. Singh, S. Kumari, A. K. Srivastava, S. Bathula, S. Dhawan, P. Dutta and A. Dhar, J. Mater. Chem. A, 2015, 3, 13986-13993.

50 M.-M. Lu, W.-Q. Cao, H.-L. Shi, X.-Y. Fang, J. Yang, Z.-L. Hou, H.-B. Jin, W.-Z. Wang, J. Yuan and M.-S. Cao, J. Mater. Chem. A, 2014, 2, 10540-10547.

51 X. Sun, J. He, G. Li, J. Tang, T. Wang, Y. Guo and H. Xue, J. Mater. Chem. C, 2013, 1, 765-777.

52 T. Ting, Y. Jau and R. Yu, Appl. Surf. Sci., 2012, 258, 3184-3190. 53 M.-S. Cao, J. Yang, W.-L. Song, D.-Q. Zhang, B. Wen, H.-B. Jin, Z.-L. Hou and J. Yuan, ACS Appl. Mater. Interfaces, 2012, 4, 6949-6956.

54 D. K. Saket, A. P. Singh, S. Pati, T. K. Gupta, V. N. Singh, S. R. Dhakate, S. Dhawan, R. K. Kotnala and R. B. Mathur, J. Mater. Chem. A, 2015, 3, 13203-13209.

55 A. P. Singh, M. Mishra, P. Sambyal, B. K. Gupta, B. P. Singh, A. Chandra and S. K. Dhawan, J. Mater. Chem. A, 2014, 2, 3581-3593.

56 S. Abbas, A. Dixit, R. Chatterjee and T. Goel, Mater. Sci. Eng., B, 2005, 123, 167-171.

57 N. Li, C. Hu and M. Cao, Phys. Chem. Chem. Phys., 2013, 15, 7685-7689. 
58 F. Meng and X. Liu, $R S C A d v ., 2015,5,7018-7022$.

59 Y.-H. Chen, Z.-H. Huang, M.-M. Lu, W.-Q. Cao, J. Yuan, D.-Q. Zhang and M.-S. Cao, J. Mater. Chem. A, 2015, 3, 12621-12625.

60 W.-L. Song, M.-S. Cao, B. Wen, Z.-L. Hou, J. Cheng and J. Yuan, Mater. Res. Bull., 2012, 47, 1747-1754.
61 J. Xiang, J. Li, X. Zhang, Q. Ye, J. Xu and X. Shen, J. Mater. Chem. A, 2014, 2, 16905-16914.

62 X. Liu, Y. Chen, X. Cui, M. Zeng, R. Yu and G.-S. Wang, J. Mater. Chem. A, 2015, 3, 12197-12204.

63 M. Rahaman, T. Chaki and D. Khastgir, J. Mater. Sci., 2011, 46, 3989-3999. 